\title{
$\mathrm{NaOH}$ 尿素前処理による麦ワラ機械パルプの改質*1
}

\author{
金 光范*2, 翟 睿*2, 朱 春鳳 $* 2$, 許 銀超*2, 王 立軍*3, \\ 王 建業*4, 中川明子*5

\section{Strength Improvement of Wheat Straw Chemi-mechanical Pulp by the $\mathrm{NaOH}$-urea Pretreatment*1}

\author{
Guangfan JiN*2, Rui ZHAI*2, Chunfeng ZHU*2, \\ Yinchao $\mathrm{XU}^{* 2}$, Lijun WANG*3, Jianye WANG*4 \\ and Akiko NAKAGAWA-IZUMI*5
}

\begin{abstract}
The NaOH-urea pretreatment system under mild temperatures was used to modify mechanical pulp properties of wheat straw, and the effects of alkali impregnation time and treatment temperature time were evaluated through single factor tests. The results showed that the optimal conditions were chosen as $\mathrm{NaOH}$ and urea concentrations of $5 \%$ and $3.5 \%$, impregnation time of $10 \mathrm{~min}$, treatment temperature of $50{ }^{\circ} \mathrm{C}$ and treatment time of $60 \mathrm{~min}$. Compared with the results of the $\mathrm{NaOH}$-pretreated chemimechanical pulp production, the refining energy consumption of the mechanical pulp prepared by the $\mathrm{NaOH}$-urea system was decreased by $14 \%$, while screened yield and brightness of the pulp were increased by $1.5 \%$ and $4.2 \%$ (point) and sheet density, tensile index and burst index were increased by $3.5 \%, 20 \%$ and $17 \%$, respectively.
\end{abstract}

Keywords: $\mathrm{NaOH}-u$ rea aqueous solution, wheat straw, chemi-mechanical pulp, refining energy.

本研究では, $\mathrm{NaOH}$ ・尿素水溶液で麦ワラを前処理して機械パルプを製造し, $\mathrm{NaOH}$ 濃度, 浸 漬時間，処理時間，処理温度などがパルプの物性に与える影響を調べた。尿素を用いない場合と 比較した結果, $\mathrm{NaOH}$ ・尿素前処理では, 解繊電力消費が $14 \%$ 削減し, 得られたパルプの精選収 率と白色度がそれぞれ $1.5 \%$ と $4.2 \%$ ポイント向上し， シート密度，引張強度および破裂強度がそ

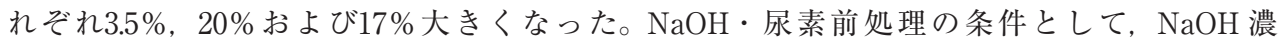
度 $5 \%$ ，尿素濃度 $3.5 \%$, 浸漬時間 10 分，処理温度 50 ㄷ，処理時間60分が最適であった。

*1 Received March 4, 2019; accepted May 18, 2019.

*2 浙江科技学院 Zhejiang University of Science and Technology, Hangzhou, Zhejiang 310023, China

*3 浙江杭化新材料科技有限公司 Zhejiang Hanghua New Materials Science \& Technology Co., Ltd, Hangzhou, Zhejiang 311300, China

*4 杭州特种纸業有限公司 Hangzhou Special Paper Industry Co., Ltd, Hangzhou, Zhejiang 311400, China

*5 筑波大学生命環境科学研究科 Graduate School of Life and Environmental Sciences, University of Tsukuba, Tsukuba, Ibaraki 305-8572, Japan

Corresponding author: G. Jin (kinkaen2000@yahoo.co.jp) 


\section{1. 緒言}

機械パルプは化学パルプに比べて, 収率が高く, 紙の嵩が高いなどの利点があるが，解繊エネルギー

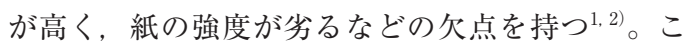
の欠点により, 機械パルプの用途が制限されている。 農業大国の中国は木材資源が不足しているが，農業 廃棄物（麦ワラ,稲わらなど）の資源が豊富である。 中国紙パルプ産業の木材資源不足の問題を解決する には, 機械パルプ生産を発展させると共に, 草本類 の利用率を向上させる必要がある。草本類は，灰分 とへミセルロースの含有量が高く, 化学パルプには 向いてない。しかし, 草本類は, 材質が緩く, 柔ら かいので，化学機械パルプの良い原料になる。

$\mathrm{NaOH}$ ・尿素 $\left(\left(\mathrm{H}_{2} \mathrm{~N}\right)_{2} \mathrm{CO}\right)$ 水溶液の処理により, 低温と低纎維濃度条件でセルロースを溶解すること が可能である ${ }^{3)}$ 。一方, $\mathrm{NaOH}$ ・チ才尿素 $\left(\left(\mathrm{H}_{2} \mathrm{~N}\right)_{2}\right.$ CS）または $\mathrm{NaOH}$ ・チ才尿素・尿素の処理により， より低温の条件で，セルロースを溶解することが可 能である ${ }^{4,5)}$ 。前報6) では, $\mathrm{NaOH}$ ・ チ才尿素・尿素 処理によるセルロースの膨潤に着目し, 高湿潤強度 紙製造に関する研究を報告した。また，低温の $\mathrm{NaOH}$ ・チオ尿素前処理を用いるタケの機械パルプ 化について検討を行っだ)。

本研究では, $\mathrm{NaOH}$ ・尿素処理によるセルロース の膨潤性に着目した。しかし, 中温（室温 $100{ }^{\circ} \mathrm{C}$ 以下）の条件でリグノセルロース材料を前処理し， 機械パルプを製造する研究は報告されてない。そこ で，タケよりも機械パルプ化が容易な麦ワラを取り 上げ， $\mathrm{NaOH}$ ・尿素前処理の機械パルプ化への影響 を明らかにすることを目的とした。

\section{2. 実験}

\section{1 試料}

麦ワラを $5 \mathrm{~cm} \times 1 \mathrm{~cm} \times 1 \mathrm{~mm}$ (長さ $\times$ 幅 $\times$ 厚 さ）に切断し，水に浸して洗浄した。洗浄後，自然 乾燥させ, 密閉容器に入れて保存した。 $\mathrm{NaOH}$, 尿 素と蒸留水を $6: 4: 90$ の重量比で混合した $\mathrm{NaOH}$ • 尿素水溶液の原液を作成 ${ }^{8)}$, 十分に密閉容器に保 存した。この原液（NaOH 濃度 6\%）を蒸留水で希 釈し， $\mathrm{NaOH}$ 濃度として，3，4，5\%の $\mathrm{NaOH}$ ・尿 素水溶液を調製した。

\section{2 方法}

\subsection{1 麦ワラの化学組成分析}

風乾した麦ワラをウィリーミルで粉砕し，40６0 メッシュにし，密閉容器に48時間保存した。これを 用い, 灰分, エタノール・ベンゼン $(1: 2 \mathrm{v} / \mathrm{v})$ 抽
出物, リグニン，ホロセルロースとペントサンを定 量した。

\subsection{2 麦ワラの前処理}

風乾麦ワラ $150 \mathrm{~g}$ （絶乾重量として）に, $\mathrm{NaOH}$ 濃度 3 6\%の $\mathrm{NaOH}$ ・ 尿素水溶液 $150 \mathrm{~g}$ を加え, 直 ちに蒸留水 $450 \mathrm{~mL}$ を加えて瀻維濃度を $20 \%$ に調製 し, 室温で攪汼して麦ワラに $\mathrm{NaOH}$ ・尿素水溶液を 5〜20分間浸透させた。これをウォータバスに入れ， $30 \sim 60{ }^{\circ} \mathrm{C}$ の一定の温度条件で, 時々攪找しながら, 前処理を行った。終了後, 麦ワラを洗浄し, 自然乾 燥させ, 収率, 灰分, エタノール・ベンゼン抽出物, リグニンとホロセルロースを定量した。

\subsection{3 麦ワラの解繊処理とパルプ分析}

残りの試料は, 研究用リファイナー（Hengke 恒 科自動化設備有限公司製 IMT-GNPM01, 東莞市, 中国）で解繊し，その際の電力消費および未精選パ ルプ収率を測定した。

得られた未精選パルプをフラットスクリーン (Hengke 恒科自動化設備有限公司製, IMT-BE01, 東莞市, 中国) で分け, 粕を除去して精選パルプの 収率を測定した。

また, 浸漬時間10分, 処理時間60分, 処理温度 $50{ }^{\circ} \mathrm{C}$ の条件で処理された麦ワラパルプを用い，ペ ントサンを定量した。

\subsection{4 麦ワラパルプの漂白処理}

精選パルプを二段の $\mathrm{NaOH}$ および尿素性過酸化 水素処理で漂白し, 漂白パルプ (BSUMP) を調製 した。漂白薬品の添加率は以下のと抢りである。

第一段 : $\mathrm{H}_{2} \mathrm{O}_{2}: 2.5 \%, \mathrm{NaOH}: 1.5 \%$, $\mathrm{MgSO}_{4}: 0.3 \%, \mathrm{Na}_{2} \mathrm{SiO}_{3}: 3.0 \%$

第二段 : $\mathrm{H}_{2} \mathrm{O}_{2}: 4.5 \%, \mathrm{NaOH}: 1.5 \%$,

$$
\mathrm{MgSO}_{4}: 0.3 \%, \mathrm{Na}_{2} \mathrm{SiO}_{3}: 3.0 \%
$$

BSUMP は吒解機（安尼麦特機器有限公司製 Valley AT-WL，山東，中国）を用い, ISO 5269-1 2005) にしたがってショッパーリーグラー度（ ${ }^{\circ} \mathrm{SR}$ ) 16 または17に吒解し，坪量 $60 \mathrm{~g} / \mathrm{m}^{2}$ の手抄き紙を作 成し, 白色度, 引張強度, 破裂強度抢よび密度を測 定した ${ }^{10)}$ 。

比較として, $\mathrm{NaOH}$ ・尿素水溶液の代わりに $\mathrm{NaOH}$ 水溶液（尿素無添加）による前処理を行い, 解繊後に漂白を行って漂白化学機械パルプ (BCMP) を調製した。

上述の二種類パルプの繊維長と直径を全自動粗繊 維測定機 (Alva 阿尔瓦有限公司製, F5800, 済南市, 中国）を用いて測定した。 


\section{3. 結果と考察}

\section{1 浸漬時間の影響}

Table 1 に示すように, 浸漬時間の増加によって, パルプ収率の低下する傾向が確認された。エ夕ノー ル・ベンゼン抽出物, リグニンと灰分の含有量は低 下したが，ホロセルロースの含有量は増加した。解 繊エネルギーは減少したが，浸漬時間が10分以上の 場合には，著しい変化は現れなかった。

化学機械パルプの収率は，一般的に80～90\%であ る ${ }^{11)}$ 。浸漬の目的は, 解繊しやすくするために, 化 学薬品を麦ワラに均一に浸透させることであり, 浸 漬時間が短いと，薬品が十分に浸透されず，麦ワラ 各成分への効果は小さい。浸漬時間増加につれて, 薬品が麦ワラに十分吸収され, 解繊エネルギーが減 少した。麦ワラは材質が緩く, 薬品が浸透しやすい。 また，浸漬時間10分後には，解繊エネルギーの変化 は著しくなかったので，最適な浸漬時間を10分とし
た。

\section{2 処理温度の影響}

Table 2 で示すように，処理温度が増加すると， パルプ収率, エ夕ノール・ベンゼン抽出物, 灰分と リグニンの含有量は減少したが，ホロセルロースの 含有量は増加する傾向が確認された。また，解繊工 ネルギーは減少するが, 最初は大きく, 処理温度が さらに高くなっても，その減少幅は小さくなった。

繊維は温度が高くなると，反応速度が速くなり， 繊維の化学成分が容易に除去され，繊維の膨潤が速 く，軟化が進み，解繊性能がよくなったと考えられ る。処理温度が $50{ }^{\circ} \mathrm{C}$ 以上になると, 解繊エネルギ 一の減少は小さかったが, 組成成分の変化は大きか った。以上の結果から, 本実験の処理温度を50 ${ }^{\circ} \mathrm{C}$ とした。

\section{$3.3 \mathrm{NaOH}$ および尿素濃度の影響}

Table 3 で示すように, $\mathrm{NaOH}$ および尿素濃度の 増加につれて, パルプ収率, エタノール・ベンゼン

Table 1. Effect of impregnation time.

\begin{tabular}{ccccccc}
\hline \hline $\begin{array}{c}\text { Impregnation } \\
\text { time }(\mathrm{min})\end{array}$ & $\begin{array}{c}\text { Refining energy } \\
(\mathrm{kWh} / \mathrm{t})\end{array}$ & $\begin{array}{c}\text { Screened pulp } \\
\text { yield }(\%)\end{array}$ & $\begin{array}{c}\text { Ethanol-benzene } \\
\text { Extractives }(\%)\end{array}$ & $\begin{array}{c}\text { Ash } \\
(\%)\end{array}$ & $\begin{array}{c}\text { Lignin } \\
(\%)\end{array}$ & $\begin{array}{c}\text { Holo-cellulose } \\
(\%)\end{array}$ \\
\hline 5 & 1025 & 90.2 & 1.9 & 3.4 & 16.5 & 80.3 \\
10 & 843 & 87.8 & 1.7 & 3.4 & 15.5 & 81.4 \\
15 & 822 & 86.6 & 1.5 & 3.2 & 14.1 & 82.5 \\
20 & 807 & 85.9 & 1.3 & 3.0 & 13.5 & 83.9 \\
\hline
\end{tabular}

$\mathrm{NaOH}$ and urea concentrations: $6 \%$ and $4 \%$, respectively ;

Treatment temperature and time after impregnation: $50{ }^{\circ} \mathrm{C}$ and $75 \mathrm{~min}$.

Table 2. Effect of treatment temperature.

\begin{tabular}{ccccccc}
\hline \hline $\begin{array}{c}\text { Treatment } \\
\text { temperature } \\
\left({ }^{\circ} \mathrm{C}\right)\end{array}$ & $\begin{array}{c}\text { Refining energy } \\
(\mathrm{kWh} / \mathrm{t})\end{array}$ & $\begin{array}{c}\text { Screened pulp } \\
\text { yield } \\
(\%)\end{array}$ & $\begin{array}{c}\text { Ethanol-benzene } \\
\text { extractives } \\
(\%)\end{array}$ & $\begin{array}{c}\text { Ash } \\
(\%)\end{array}$ & $\begin{array}{c}\text { Lignin } \\
(\%)\end{array}$ & $\begin{array}{c}\text { Holo-cellulose } \\
(\%)\end{array}$ \\
\hline 30 & 1073 & 92.7 & 1.5 & 4.3 & 17.4 & 80.1 \\
40 & 962 & 91.2 & 1.5 & 3.5 & 16.9 & 81.4 \\
50 & 856 & 88.2 & 1.4 & 3.4 & 15.6 & 82.4 \\
60 & 829 & 86.3 & 1.2 & 3.0 & 15.0 & 83.8 \\
\hline
\end{tabular}

$\mathrm{NaOH}$ and urea concentrations: $6 \%$ and $4 \%$, respectively ;

Impregnation time before treatment : $10 \mathrm{~min}$;

Treatment time: $75 \mathrm{~min}$.

Table 3. Effect of $\mathrm{NaOH}$ and urea concentrations.

\begin{tabular}{cccccccc}
\hline \hline $\begin{array}{c}\text { NaOH } \\
\begin{array}{c}\text { concentration } \\
(\%)\end{array}\end{array}$ & $\begin{array}{c}\text { Urea } \\
\text { concentration } \\
(\%)\end{array}$ & $\begin{array}{c}\text { Refining } \\
\text { energy } \\
(\mathrm{kWh} / \mathrm{t})\end{array}$ & $\begin{array}{c}\text { Screened } \\
\text { pulp yield } \\
(\%)\end{array}$ & $\begin{array}{c}\text { Ethanol-benzene } \\
\text { extractives } \\
(\%)\end{array}$ & $\begin{array}{c}\text { Ash } \\
(\%)\end{array}$ & $\begin{array}{c}\text { Lignin } \\
(\%)\end{array}$ & $\begin{array}{c}\text { Holo- } \\
\text { cellulose } \\
(\%)\end{array}$ \\
\hline 3 & 2.0 & 1106 & 93.0 & 1.9 & 4.0 & 18.0 & 80.1 \\
4 & 2.8 & 980 & 91.0 & 1.5 & 3.9 & 17.6 & 81.7 \\
5 & 3.5 & 863 & 89.3 & 1.3 & 3.5 & 16.4 & 82.3 \\
6 & 4.0 & 848 & 86.8 & 1.2 & 3.3 & 14.7 & 84.1 \\
\hline
\end{tabular}

Impregnation time: $10 \mathrm{~min}$;

Treatment temperature and time: $50{ }^{\circ} \mathrm{C}$ and 75 min, respectively. 
抽出物, 灰分とリグニンの含有量は減少したが, ホ ロセルロースの含有量は増加する傾向が確認され た。解繊エネルギーは $\mathrm{NaOH}$ および尿素濃度の増 加につれて大きく減少したが, $\mathrm{NaOH}$ および尿素濃 度が $5 \%$ および $3.5 \%$ を超えると, 減少の程度は緩く なった。 $\mathrm{NaOH}$ 尿素水溶液はアルカリ溶液であり, 麦ワラ中の一部のリグニンとへミセルロースなどの アルカリ可溶性物質を溶解するので, $\mathrm{NaOH}$ および 尿素濃度の増加につれて, 麦ワラの組成成分の除去 率は上昇し, パルプ収率は減少した。しかし, 反応 温度は中温の範囲なので, 麦ワラ中のセルロースの 分解が起こる温度に達していない。また, へミセル ロースの反応性はリグニンに及ばないので ${ }^{12)}$, 処理 後ホロセルロースの含有量は上昇したと考えられる。

草本類はリグニン含有量が高くなると, 解繊が難 しくなる。脱リグニンにより, 麦ワラの軟化が進み, 解繊性能が改善され, 解繊エネルギーが減少する。 しかし, 本研究の処理条件では, 多量の脱リグニン は観察されなかった。したがって，一部の脱リグニ ンが解繊エネルギー減少の主な原因ではないと考え られる。

本研究の処理では, $\mathrm{NaOH}$ 水溶液の濃度が低いの で，セルロースの非晶区域の一部しか膨閏が起こら ないと考えられるが, 一部でも膨閏すれば, これに より繊維の柔軟性が改善されると期待できる。
$\mathrm{NaOH}$ 水溶液により膨潤した麦ワラは尿素によりさ らに軟化するので，このことが解繊エネルギー減少 の主な原因だと考えられる。これが $\mathrm{NaOH}$ ・尿素水 溶液による処理の利点である。

$\mathrm{NaOH}$ および尿素濃度が増加するにつれて, 繊維 の膨潤は進むが，膨潤は $\mathrm{NaOH}$ および尿素量が一 定の時, 飽和状態になるので, 膨潤の上昇率は大き くないと考えられる ${ }^{13)}$ 。また, $\mathrm{NaOH}$ は麦ワラ組成 成分の除去に使用される ${ }^{14)}$ 。以上の結果から，最適 な濃度は, $\mathrm{NaOH}$ 濃度 $5 \%$ で尿素濃度 $3.5 \%$ であると 考えられる。

\section{4 処理時間の影響}

Table 4 で示すように, 処理時間の増加につれて, パルプ収率, エタノール・ベンゼン抽出物, 灰分と リグニンの含有量は減少する傾向が確認されたが, ホロセルロースの含有量は増加し, 解繊エネルギー は小さくなった。処理時間が 60 分を超えると, 解繊 エネルギーの減少幅が小さくなるとともに, ホロセ ルロースの増加幅も小さくなった。以上の結果から, 処理時間を60分とした。

\section{5 化学組成分析}

Table 5 は, 本研究の最適な条件 $(\mathrm{NaOH}$ および 尿素濃度： $5 \%$ および $3.5 \%$, 浸漬時間 10 分, 処理時 間 60 分, 処理温度 $50{ }^{\circ} \mathrm{C}$ ) で得られたパルプの化学組 成を示している。この結果からみると, エタノール・

Table 4. Effect of treatment time.

\begin{tabular}{ccccccc}
\hline \hline $\begin{array}{c}\text { Treatment time } \\
(\mathrm{min})\end{array}$ & $\begin{array}{c}\text { Refining energy } \\
(\mathrm{kWh} / \mathrm{t})\end{array}$ & $\begin{array}{c}\text { Screened pulp } \\
\text { yield } \\
(\%)\end{array}$ & $\begin{array}{c}\text { Ethanol-benzene } \\
\text { extractives } \\
(\%)\end{array}$ & $\begin{array}{c}\text { Ash } \\
(\%)\end{array}$ & $\begin{array}{c}\text { Lignin } \\
(\%)\end{array}$ & $\begin{array}{c}\text { Holo- cellulose } \\
(\%)\end{array}$ \\
\hline 30 & 1068 & 93.1 & 1.5 & 3.9 & 18.2 & 80.0 \\
45 & 954 & 92.3 & 1.4 & 3.8 & 17.3 & 80.5 \\
60 & 866 & 88.7 & 1.3 & 3.7 & 16.0 & 82.9 \\
75 & 842 & 86.6 & 1.3 & 3.3 & 15.1 & 83.6 \\
\hline
\end{tabular}

$\mathrm{NaOH}$ and urea concentrations: $5 \%$ and $3.5 \%$, respectively ;

Impregnation time: $10 \mathrm{~min}$;

Treatment temperature: $50{ }^{\circ} \mathrm{C}$.

Table 5. Chemical composition of wheat straw and chemi-mechanical pulp.

\begin{tabular}{cccccc}
\hline \hline & $\begin{array}{c}\text { Ethanol-benzene } \\
\text { extractives } \\
(\%)\end{array}$ & $\begin{array}{c}\text { Ash } \\
(\%)\end{array}$ & $\begin{array}{c}\text { Lignin } \\
(\%)\end{array}$ & $\begin{array}{c}\text { Holo- } \\
\text { cellulose } \\
(\%)\end{array}$ & $\begin{array}{c}\text { Pentosan } \\
(\%)\end{array}$ \\
\hline Wheat straw & 2.3 & 4.3 & 20.5 & 74.9 & 25.9 \\
Pulp $^{1)}$ & 1.2 & 3.3 & 14.2 & 73.5 & 25.1 \\
& $(1.3)^{2)}$ & $(3.7)^{2)}$ & $(16.0)^{2)}$ & $(82.9)^{2)}$ & $(28.3)^{2)}$ \\
\hline
\end{tabular}

1) Obtained under conditions of $\mathrm{NaOH}$ and urea concentrations : $5 \%$ and $3.5 \%$, respectively; Impregnation time: $10 \mathrm{~min}$; Treatment temperature and time: $50{ }^{\circ} \mathrm{C}$ and $60 \mathrm{~min}$.

2) Based on pulp weight. 
ベンゼン抽出物, 灰分とリグニンの含有量は, 処理 後に著しく減少したが，ホロセルロースとペントサ ンの減少は小さかった。アルカリはエタノール・ベ ンゼン抽出物中の有機酸, 灰分中のケイ酸塩と反応 するので，これらの除去率が高い。リグニンの一部 はアルカリ可溶性物質であり，アルカリと反応する ので, 同じく減少が大きい。アルカリ条件で, アセ チル基が容易に脱落するので，へミセルロースの減 少が予想されたが, 結果を見る限り, この反応性は リグニンの減少に及ばなかった。処理後, パルプの ヘミセルロース含有量 (比率) は上昇した。セルロ ースは高温の条件で加水分解とピーリング反応が起 きるが，本研究で用いた $50{ }^{\circ} \mathrm{C}$ の処理温度では，処 理前後にセルロースの含有量はほぼ変わらなかった。

\subsection{BSUMP と BCMP のパルプ強度の比較}

Table 6 には, BCMP と比較したパルプ物性を示 す。吒解度一定の時, BSUMP は BCMP と比べて, 解繊エネルギーは14\%低かった。BSUMP の未精選 パルプ収率は BCMPより低かった。

$\mathrm{NaOH}$ ・尿素水溶液処理により多くのリグニンが 除去された。しかし, 解繊エネルギーの減少は, リ グニン除去が主な原因ではなく, 尿素のセルロース に対する膨潤作用が優れていることにより，纎維の 柔軟性が向上したことが原因であると考えられる。

一方, BSUMP の精選パルプ収率は BCMPより 1.5 \%（ポイント）高かった。これは $\mathrm{NaOH} ・$ 尿素前処 理により,繊維化が容易になったことが原因である。 さらに, BSUMP の白色度は BCMP より 4.2\%（ポ イント）高かった。これは $\mathrm{NaOH}$ ・尿素水溶前処理 により, 繊維の反応性が改善され, より容易に $\mathrm{H}_{2} \mathrm{O}_{2}$ と反応した結果である ${ }^{15)}$ 。

BSUMP の物理強度はBCMP と比較して, 引張 強度が $20 \%$, 破裂強度が $17 \%$ 向上した。これは $\mathrm{NaOH}$ ・尿素水溶液処理により, より多くの水酸基

Table 6. Pulping properties of BSUMP and BCMP.

\begin{tabular}{ccc}
\hline \hline & BSUMP & $\begin{array}{c}\text { BCMP } \\
\text { (Comparison) }\end{array}$ \\
\hline Beating degree, ${ }^{\circ} \mathrm{SR}$ & 17 & 16 \\
Refining energy, $\mathrm{kWh} / \mathrm{t}$ & 866 & 1012 \\
Unscreened yield, \% & 89.0 & 91.5 \\
Screened yield, \% & 73.3 & 71.8 \\
Brightness, \% & 70.4 & 66.2 \\
Tensile index, Nm/g & 25.8 & 21.4 \\
Burst index, $\mathrm{kPa} \mathrm{m}^{2} / \mathrm{g}$ & 2.6 & 2.3 \\
Folding, number & 4 & 3 \\
Bulkiness, $\mathrm{cm}^{3} / \mathrm{g}$ & 2.3 & 2.5 \\
Fiber length, $\mathrm{mm}$ & 0.63 & 0.65 \\
Fiber width, $\mu \mathrm{m}$ & 28.5 & 26.8 \\
\hline
\end{tabular}

が繊維表面に現れ, 繊維間の結合強度改善に貢献し たことが原因だと考えられる。しかし，リグニンの 含有量が依然高く, 耐折度は大きく改善されなかっ た。また, 䋊維の結合が緊密になり, 紙の高が $8 \%$ 低くなった（密度が $3.5 \%$ 高くなった）。

\section{4. 結 論}

（1） 機械パルプ化用麦ワラの $\mathrm{NaOH}$ ・尿素前処理 の最適条件は, $\mathrm{NaOH}$ 濃度 5\%, 尿素濃度 $3.5 \%$, 浸漬時間 10 分, 処理温度 $50{ }^{\circ} \mathrm{C}$, 処理時間 60 分で ある。

（2）尿素を用いない場合と比較した結果， $\mathrm{NaOH}$ ・ 尿素前処理では, 解繊電力消費が $14 \%$ 削減し, 得られたパルプの精選収率と白色度がそれぞれ $1.5 \%$ と $4.2 \%$ 向上し, シート密度, 引張強度およ び破裂強度がそれぞれ $3.5 \%$ ，20\%および $17 \%$ 大 きくなった。

\section{謝辞}

本研究は，2019年度浙江省重点研究開発プロジェ クト - 農業廃棄物資源化利用技術研究（課題番号 2019C02073）より実施した。また，浙江省基礎公益 研究計画プロジェクト（課題番号 LQY19E030001） の援助を受けた。関係各位に心より御礼申し上げる。

\section{引用文献}

1) Kenealy, W., Horn, E., Houtman, C.: Vaporphase diethyl oxalate pretreatment of wood chips. Part 1: energy savings and improved pulps. Holzforschung 61 (3), 223-229 (2007).

2) Liu, Y., Liu, M., Li, H. : Characteristics of high yield pulp fibers by xylanase treatment. Cellulose 23(5), 3281-3289(2016).

3) Mao, Y., Zhou, J., Cai, J.: Effects of coagulants on porous structure of membranes prepared from cellulose in $\mathrm{NaOH} /$ urea aqueous solution. J. Membrane Sci 279(1-2), 246-255 (2006).

4) Ruan, D., Zhang, L., Mao, Y.: Microporous membranes prepared from cellulose in $\mathrm{NaOH}$ /thiourea aqueous solution. J. Membrane Sci 241 (2), 265-274 (2004).

5) Jin, HJ., Zha, C., Gu, L. : Direct dissolution of cellulose in $\mathrm{NaOH} /$ thiourea/urea aqueous solution. Carbohyd. Res 342(6), 851-858 (2007).

6）金 光范, 翟 点, 寇 顺利, 王 慧丽, 中川明 
子： $\mathrm{NaOH}$-チオ尿素-尿素溶液を用いた高湿 潤強度紙製造に関する研究. 木材学会誌 64 (5), 213-219 (2018).

7）金 光范, 翟 点, 寇 顺利, 吴 安波, 中川明 子： $\mathrm{NaOH}$ ・チオ尿素前処理が夕ケ (Phyllostachys pubescens) 機械パルプの物性に与える 影響. 木材学会誌 65(1), 19-24 (2019).

8) Zhou, J., Zhang, L., Cai, J.: Cellulose microporous membranes prepared from $\mathrm{NaOH} /$ urea aqueous solution. J. Membrane Sci 210 (1), 77-90 (2002).

9) ISO5269-1 2005: Pulps-Preparation of laboratory sheets for physical testing - Part 1: Conventional sheet-former method. International Organization for Standardization (2005).

10) Zhai, R., Zhou, X. : Enhanced effect of NaOH/ Thiourea/Urea aqueous solution on paper strength of high yield pulp . Bio Resources 9 (2), 2154-2166 (2014).

11) Yang, Q., Zhan, H., Wang, S. : Modification of eucalyptus CTMP fibres with white-rot fungus trametes hirsute-Effects on fibre morphology and paper physical strengths. Bioresour. Technol 99(17), 8118-8124 (2008).

12) Jiang, H., Han, B., Ge, J. : Enhancement in the enzymatic digestibility of hybrid poplar with poor residual hemicelluloses after $\mathrm{Na}_{2} \mathrm{SO}_{3}$ pretreatment. Bioresour. Technol 180, 338344 (2015).

13) Killmann W., Koh, M.P.: Oil palm stem densification using ammonia treatment: A preliminary study. J. Tropical Forest Sci 1 (1), 1-10 (1988).

14) Zhai, H., Lee, Z.: Ultrastructure and topochemistry of delignification in alkaline pulping of wheat straw. J. Wood Chem. Technol 9(5), 387-406 (1989).

15) Zhang, L., Ruan, D., Zhou, J.: Structure and properties of regenerated cellulose films prepared from cotton linters in $\mathrm{NaOH} /$ urea aqueous solution. J. Ind. Eng. Chem. Res 40 (25), 5923-5928 (2001). 